\title{
PENGEMBANGAN MEDIA PEMBELAJARAN SISTEM WIPER OTOMATIS (RAIN SENSOR) UNTUK MENINGKATKAN HASIL BELAJAR SISWA KELAS XII DI SMK ISLAM SUDIRMAN GRABAG MAGELANG
}

\author{
Oleh : Danik Supriyadi, Suyitno Pendidikan Teknik Otomotif Fakultas Keguruan dan \\ Ilmu Pendidikan Universitas Muhammadiyah Purworejo. \\ E-mail : ilhamnajwa0223@gmail.com, yitno@umpwr.ac.id
}

\section{ABSTRAK}

Penelitian ini bertujuan : (1) untuk mengetahui kelayakan dan hambatan dalam pembuatan media pembelajaran, (2) untuk meningkatkan hasil belajar siswa sesuai dengan kriteria ketuntasan minimal (KKM) sekolah sebesar 75 pada mata pelajaran sistem wiper dengan mengembangkan media pembelajaran trainer konvensional menjadi media pembelajaran trainer sistem wiper otomatis. Jenis penelitian yang digunakan Research and Development.

Subyek dalam penelitian ini merupakan siswa kelas XII TKR SMK Islam Sudirman Grabag Magelang dengan kelas eksperimen (XII TKR B) yang berjumlah 25 siswa dan kelas kontrol (XII TKR A) yang berjumlah 24 siswa. Pengumpulan data dilakukan dengan menggunakan metode angket dan tes. Angket berisi tanggapan siswa dengan 3 indikator dan 6 pernyataan dan tes berisi 20 butir soal. Sebelum digunakan sebagai instrumen penelitian, angket dan tes di uji cobakan secara terbatas kepada 20 siswa jurusan teknik kendaraan ringan untuk memperoleh validitas instrumen. Penghitungan instrumen angket dan tes menggunakan rumus validitas point biserial atau $Y_{p b i s}$ dengan taraf signifikansi $5 \%$.

Hasil penelitian sebagai berikut : Uji coba terbatas terhadap instrumen menghasilkan $r_{\text {pbis }}>r_{\text {tabel }}$ dimana $r_{11}=0,67031$ dan $r_{\text {tabel }}=0,444$ dengan nilai rata-rata $72,708 \%$ atau dengan kategori valid. Prosedur pengembangan sistem wiper otomatis di SMK Islam Sudirman Grabag Magelang dimulai dari tahap observasi, dilanjutkan dengan pembuatan media pembelajaran trainer sistem wiper otomatis pada mata pelajaran sistem wiper dan washer, langkah pembuatan media tersebut dimulai dari : (1) perencanaan, sketsa alat yang akan dihasilkan ditentukan, (2) penyediaan bahan, (3) pembuatan media, (4) uji kelayakan alat dengan uji terbatas melalui penggalian tanggapan siswa terkait alat tersebut, (5) revisi tahap I, (6) uji validasi ahli media, (7) revisi tahap 2, (8) implementasi, dimana alat yang telah dihasilkan siap untuk digunakan didalam penelitian. Hambatan didalam pembuatan media pembelajaran yakni modul yang kurang awet karena menggunakan bahan bahan yang tersedia di pasaran tanpa melihat kualitas. Peningkatan hasil belajar siswa pada kelas eksperimen sebesar 7,6\%, dengan nilai rata-rata 76,00 (sudah memenuhi KKM) dengan 
demikian menunjukkan siswa lebih aktif dan termotivasi dengan adanya media pembelajaran trainer sistem wiper otomatis. dan nilai rata-rata siswa pada kelas kontrol sebesar 68,12 (belum memenuhi KKM).

Kata Kunci : Pengembangan, Media pembelajaran, Trainer, Hasil Belajar

\section{PENDAHULUAN}

Pendidikan merupakan salah satu gambaran tentang kualitas sumber daya manusia suatu bangsa, pendidikan yang berkualitas akan mendorong kemajuan dan keberadaban bangsa, terutama di Indonesia yang mempunyai sumber daya manusia produktif yang melimpah karena jumlah penduduk yang sangat banyak, kekayaan sumber daya manusia produktif ini akan berguna jika pendidikannya di perhatikan secara serius, akan tetapi jika sumber daya manusia ini tidak di berikan pendidikan secara baik maka akan membawa dampak yang buruk bagi keberlangsungan kehidupan berikutnya. oleh karena itu pendidikan di Indonesia harus mampu beradaptasi dengan tuntutan dunia kerja baik di dalam skala nasional maupun internasional bahkan pendidikan pun harus mampu mengaplikasikan setiap perkembangan teknologi kepada peserta didiknya.

SMK Islam Sudirman Grabag Magelang merupakan salah satu sekolah kejuruan yang berada di kabupaten Magelang tepatnya di desa Banyusari Grabag Magelang. Sekolah ini mempunyai dua program bidang keahlian yaitu Program keahlian Teknik Kendaraan Ringan (TKR) dan Program Keahlian Tata Boga (TB), seperti sekolah lainnya bahwa disetiap tengah semester dan akhir semester dilaksanakan evaluasi belajar menyeluruh untuk memantau perkembangan pengetahuan peserta didik selama kurun waktu tersebut, hasil evaluasi siswa ini selain untuk melihat hasil belajar peserta didik tetapi digunakan untuk mengevaluasi proses pembelajaran yang telah dilaksanakan, hal ini bertujuan untuk mengetahui kekurangan dan kelebihan dari proses belajar yang sudah terlaksana.

Pembelajaran pada prosesnya akan mempengaruhi kualitas dalam menentukan keberhasilan pendidikan. Dalam proses pembelajaran terdapat beberapa komponen yang saling berkaitan, apabila salah satu dari komponen tersebut tidak ada, maka proses belajar mengajar tidak dapat bekerja dengan lancar. Komponen-komponen tersebut dapat dikelompokkan menjadi tiga kategori utama, yaitu (a) guru (pendidik), (b) materi pembelajaran, dan (c) peserta didik. Peserta didik adalah objek yang unik dan memiliki keragaman dalam hal kecakapan maupun kepribadian. Dalam proses pembelajaran terjadi 
interaksi antara guru dengan siswa, agar guru bisa mengidentifikasi karaktersiswa, guru dapat menerapkan metode pembelajaran yang sesuai dengan karakteristik siswa. Materi pembelajaran adalah tali penyambung interaksi antara guru dan siswa. Materi pembelajaran akan menentukan seberapa besar hasil belajar siswa. Materi pembelajaran yang telah diinovasi oleh guru menjadi materi yang menarik dan interaktif, yang dapat merangsang siswa untuk lebih aktif dan menjadikan siswa menjadi lebih paham terhadap pelajaran yang sedang mereka pelajari. Peran guru dalam mengembangkan materi pembelajaran adalah hal yang sangat vital dalam proses pembelajaran

Dari beberapa alasan tersebut di atas, maka akan diadakan penelitian dengan judul "PENGEMBANGAN MEDIA PEMBELAJARAN SISTEM WIPER OTOMATIS (RAIN SENSOR) UNTUK MENINGKATKAN HASIL BELAJAR SISWA KELAS XII TKR SMK ISLAM SUDIRMAN GRABAG MAGELANG"

\section{METODE PENELITIAN}

Jenis penelitian yang digunakan adalah penelitian dan pengembangan atau Research and Development,dengan model 4D.

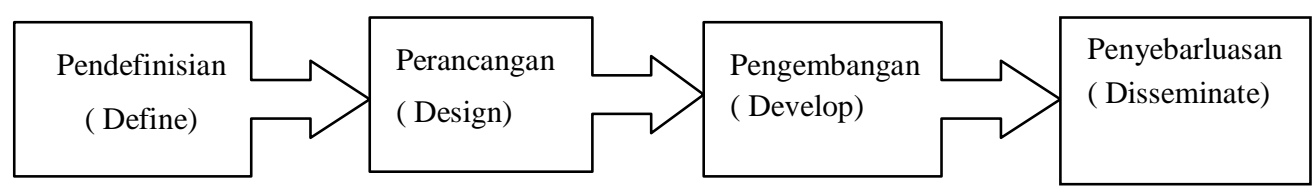

Gambar 1. Langkah - langkah penelitian dan pengembangan 4D

1. Define (Pendefinisian)

Pada tahap ini dilakukan untuk menetapkan dan mendefiniskan syarat syarat pengembangan atau analisis kebutuhan. Analisis ini biasa dilakukan dengan cara melalui studi literature atau penilaian pendahuluan, menurut Thiagaranja (Suyitno, 154), menganalisi 5 kegiatan yang dilakukan pada tahap define yaitu: 1) analisis ujung depan (front and analysis), 2) analisis siswa (learner analysis), 3) analisi tugas (task analysis), 4) analisis konsep (concept analysis), dan 5) perumusan tujuan pembelajaran (specifying instructional analysis). Dengan tahap define ini diharapkan tepat sasaran dengan hasil yang diinginkan. 
Adapun ke empat tahap tersebut dapat dijabarkan sebagai berikut :

1) Front ana analysis

Yaitu guru melakukan diagnosis awal untuk meningkatkan efisiensi dan keaktifan pembelajaran.

2) Learner analysis

Yaitu guru mempeelajari karakter peserta didik seperti kemampuan, motivasi belajar, latar belakang pengalaman, dsb.

3) Task analysis

Yaitu guru menganalisis tugas pokok yang harus dikuasai pesrta didik agar peserta didik dapat mencapai kompetensi minimal.

4) Concept analysis

Yaiut menganalisis konsep yang akan digunakan untuk mengajar, menyusun langkah-langkah yang akan dilakukan secara rasional.

5) Specifying instructional objectives

Yaitu menulis tujuan pembelajaran, perubahan perilaku yang diharapkan setelah belajar dengan kata-kata operasional.

2. Design (Perancangan)

Tahap ini bertujuan untuk merancang perangkat pembelajaran, menurut tThiagarajan, dkk (Suyitno, 156) terdapat 4 langkah dalam penyususnan tahap design yaitu (1). Penyusunan standar tes (criteriontest construction), (2) pemilihan media (media selection) yang sesuai dengan kerakteristik materi dan tujuan pembelajaran, (3). Pemilihan format (format selection), yakni mengkaji format-format bahan ajar yang telah ada dan menetapkan bahan ajar yang akan dikembangkan, (4) membuat rancangan awal (initial design).

3. Develop (Pengembangan)

Pengembangan produk dapat menggunakan dua kegiatan yaitu expert appraisal yaitu tahap memvalidasi kelayakan rancangan produk dan developmentaling testing yaitu uji coba rancangan produk pada sasaran yang sesungguhnya. Sehingga dapat menghasilkan produk yang efektif untuk pembelajaran.

4. Disseminate (Penyebar luasan)

Tahap dessiminate terbagi dalam tiga kegiatan Thiagarajan (Suyitno, 158) yaitu (1) validation testing, (2) packaging, (3) diffusion and adoption. Tahap ini bertujuan untuk mengukur keefektifan produk 
yang dihasilkan sehingga produk tersebut dapat dikemas dengan baik agar mempermudah penggunaan dan meningkatkan daya serap pembelajaran.

Penelitian ini dilaksanakan di SMK Islam Sudirman Grabag Magelang. Waktu pelaksanaan penelitian pada bulan November 2019.Subjek penelitian ini menggunakan siswa kelas XII TKR A dan kelas XII TKR B SMK Islam Sudirman Grabag Magelang dengan materi Sistem Penghapus Kaca.

Untuk menentukan kesimpulan hasil yang telah dicapai maka ditetapkan kriteria sebagai berikut :

Tabel 1. Kriteria validasi media

\begin{tabular}{|c|c|c|}
\hline $\begin{array}{c}\text { Kriteria } \\
\text { Interpretasi }\end{array}$ & Persentase & Kriteria \\
\hline A & $80 \%-100 \%$ & Valid \\
B & $60 \%-79 \%$ & Cukup valid \\
C & $50 \%-59 \%$ & Kurang valid / Revisi \\
D & $<50 \%$ & Tidak valid / Diganti \\
\hline
\end{tabular}

Rumus untuk mengolah data tanggapan ahlimedia dan ahli materi sebagi berikut :

$$
\text { Hasil skor }=\frac{\text { Skor Jawaban Responden }}{\text { Skor Keseluruhan }} \times 100
$$

1. Analisis Data Tes

a. Menghitung nilai tes

Untuk dapat memberikan makna dan pengambilan keputusan sebagai pedoma dalam pengambilan nilai, digunakan ketetapan sebagai berikut : 
Tabel 2. Arti tingkat penguasaan yang dicapai

\begin{tabular}{|c|c|c|}
\hline $\begin{array}{c}\text { Kriteria } \\
\text { Interpretasi }\end{array}$ & Persentase & Kriteria \\
\hline A & $90 \%-100 \%$ & Baik Sekali \\
B & $80 \%-89 \%$ & Baik \\
C & $70 \%-79 \%$ & Cukup \\
D & $<70 \%$ & Kurang \\
\hline
\end{tabular}

b. Uji t

Uji-t digunakan untuk membandingkan rata-rata hasil belajar kelompok eksperimen dan kelompok kontrol. Dengan rumus sebagai berikut :

$$
t=\frac{M_{X}-M_{Y}}{\sqrt{\left(\frac{\sum X^{2}+\sum Y^{2}}{N_{X}+N_{Y}-2}\right)\left(\frac{1}{N_{X}}+\frac{1}{N_{Y}}\right)}}
$$

Keterangan :

$$
\begin{aligned}
& \mathrm{M}=\text { nilai rata-rata hasil per kelompok } \\
& \mathrm{N}=\text { banyaknya subjek } \\
& \mathrm{X}=\text { deviasi setiap nilai } X_{2} \text { dan } X_{1} \\
& \mathrm{Y}=\text { deviasi setiap nilai } y_{2} \text { dari mean } y_{1}
\end{aligned}
$$

\section{HASIL PENELITIAN DAN PEMBAHASAN}

Indikator untuk ahli metri meliputi : keseuaian materi dengan SK dan KD, Keakuratan matri, Keingij tahuan siswa, Teknik dan pendukung penyajian, penyajian pembelajaran, hakikat kontekstual dankomponen kontekstual, Validasi ahli materi dilakukan untuk memperoleh masukan materi yang akan dikembangkan.Pada tahapan ini instrumen berupa materi mulai dari perangkat pembelajaran sampai kepada instrumen tes berupa angket yang akan digunakan dilihat dan direvisi oleh peneliti sesuai dengan arahan dari ahli materi. Hasilnya valid untuk digunakan. 
Validasi ahli media dilakukan untuk memperoleh masukan media yang dikembangkan. Hasil dari validasi ahli masuk dalam kriteria interpretasi $A$ atau kriteria valid, Adapun indicator yamg digunakan meliputi : konstruksi alat peraga, pewarnaan stand, design komponen, kepraktisan, kemudahan dalam penggunaan.

1. Data Uji Coba Terbatas dan Tanggapan Siswa

Uji coba terbatas dan Tanggapan Siswa dilakukan untuk memperoleh penilaian berupa tanggapan dari beberapa siswa terkait dengan media pembelajaran yang akan digunakan, tanggapan tersebut dijadikan acuan untuk merevisi media pembelajaran sebelum di uji cobakan kepada tahap yang lebih luas.

Uji coba terbatas dilakukan pada tanggal 4 november 2019 di SMK Islam Sudirman Grabag Magelang yang diikuti oleh 20 siswa dari jurusan Teknik Kendaraan Ringan. Didalam melakukan uji coba trainer menggunakan sebuah angket untuk melakukan penilaian, dengan hasil persetase $72,71 \%$ dengan kategori cukup valid.

2 Hasil Analisis Data Uji Coba Terbatas dan Tanggapan Siswa

Uji coba angket tanggapan siswa terkait media pembelajaran menggunakan 3 indikator dan 6 pernyataan, hasil validitas menggunakan rumus $Y_{p b i}$ diperoleh $r_{\text {tabel }}=0,444$ serta diperoleh nilai reliabilitas sebesar $r_{11}=0,67031$ dengan atau kategori reliabilitas tinggi, pernyataan dinyatakan valid apabila $r_{\text {pbis }}>r_{\text {tabel }}$ dengan taraf signifikan 5\%, dari hasil tersebut alat peraga bisa dipakai untuk penelitian yang lebih luas. Uji coba instrumen tes (soal) dihasilkan data sebagai berikut :

a. Tingkat Kesukaran

Terkait klasifikasi yang dihasilkan dari masing-masing soal, tergantung dari sejauh mana siswa dalam memahami materi selama proses pembelajaran disekolah, dari jumlah soal sebanyak 20,

b. Daya Pembeda

Hasil perhitungan daya pembeda dari instrumen soal didapatkan soal dengan kriteria jelek sebanyak 6 soal, cukup sebanyak 13 soal, baik sebanyak 1 soal dan baik sekali sebanyak 0 soal.

c. Validitas

Didalam penelitian ini digunakan rumus validitas point biserial atau $Y_{\text {pbis }}$ yakni : 


$$
\Gamma_{p b i s}=\frac{M p-M t}{S t} \sqrt{\frac{p}{q}}
$$

Dari hasil perhitungan 20 soal diperoleh 18 soal yang valid dan 2 soal yang tidak valid.

Berdasarkan hasil evaluasi penelitian yang telah dilakukan, kita bisa melihat hasil belajar dari pengembangan media pembelajaran wiper otomatis (rain sensor) pada kelas control XII TKR A dan kelas eksperimen XII TKR B

Tabel 11. Hasil belajar kelas kontrol dan kelas eksperimen

\begin{tabular}{|l|c|c|}
\hline Kelas & Jumlah siswa & Rata-rata \\
\hline Kontrol & 24 & 68.12 \\
\hline Eksperimen & 25 & 76.00. \\
\hline
\end{tabular}

Berdasarkan data pada table diatas bahwa hasil belajar siswa pada kelas kontrol dan kelas eksperimen dengan nilai rata - rata kelas kontrol 68.12 dan rata-rata kelas eksperimen 76.00. Dapat disimpulkan bahwa media pembelajaran wiper otomatis layak digunakan.

Hasil uji normalitas perbandingan minat belajar kelas eksperimen dan kelas kontrol diperoleh $p=0,176$, karena $p>0,05$ menunjukkan kedua kelompok berdistribusi normal. Pada bagian uji homogenitas varian, diperoleh $\mathrm{X}$ hitung $=$ 2,021 dan $X$ tabel 5,991. karena $F$ hitung < $F$ tabel maka disimpulkan kedua kelompok memiliki varian homogen. Hasil uji T perbandingan hasil belajar kelas eksperimen dan kelas kontrol diperoleh Thitung sebesar 3,966 dengan $\alpha=0,05$ atau $\mathrm{T}$ hitung sebesar 3,966 dan $\mathrm{T}$ tabel 2,011 menunjukkan ada perbedaan minat belajar antara kelas eksprimen dan kelas kontrol, artinya rata - rata hasil belajar kelas eksperimen lebih tinggi dibandingkan kelas kontrol.

Berdasarkan perhitungan statistik diatas, maka dapat disimpulkan bahwa penggunaan media pembelajaran wiper otomatis (rain sensor) berpengaruh positif terhadap hasil belajar siswa dan juga terdapat peningkatan hasil belajar siswa kelas XII SMK Islam Sudirman Grabag Magelang.

\section{KESIMPULAN}

Berdasarkan pada rumusan masalah, maka didapatkan kesimpulan sebagai berikut : 
Prosedur pengembangan sistem wiper otomatis di SMK Islam Sudirman Grabag Magelang dimulai dari tahap observasi, dari tahapan ini dihasilkan nilai rata-rata kelas hasil belajar sistem wiper otomatis dibawah nilai ketuntasan minimal (KKM). Belum tuntasnya hasil belajar tersebut terkait beberapa faktor, salah satu faktornya adalah minimnya media pembelajaran yang digunakan dalam pembelajaran. Dari hasil data observasi tersebut kemudian dilakukan langkah berupa pembuatan alat peraga sistem wiper otomatis dengan harapan dapat meningkatkan hasil belajar siswa, langkah pembuatan media tersebut dimulai dari : (1) perencanaan, disini sketsa alat yang akan dihasilkan ditentukan terlebih dahulu, (2) penyediaan bahan, pada fase ini bahan yang dibutuhkan dilengkapi sesuai dengan konsep sketsa atau perencanaan, (3) pembuatan media, (4) uji kelayakan alat dengan uji terbatas melalui penggalian tanggapan siswa terkait alat tersebut, (5) revisi tahap I, (6) uji validasi ahli media, (7) revisi tahap 2, (8) implementasi, dimana alat yang telah dihasilkan siap untuk digunakan didalam penelitian.

Berdasarkan tanggapan ahli media dengan hasil penilaian $91,6 \%$ atau masuk dalam kriteria interpretasi $A$ atau kriteria valid berarti layak untuk digunakan. Hambatan didalam pembuatan media pembelajaran sistem wiper otomatis yakni pembuatan modul wiper otomatis karena bahan bahan komponen penyusun modul hanya mengandalkan komponen yang ada dipasaran.sehingga kadang IC nya mudah rusak.

Peningkatan hasil belajar siswa pada kelas kontrol dan kelas eksperimen adalah $7,6 \%$, dengan nilai sebesar 76,00 , hasil tersebut menunjukkan rata-rata nilai didalam kelas sudah melebihi nilai kriteria ketuntasan minimal yakni 75. Dari hasil uji coba terbatas terkait tanggapan siswa pada media pembelajaran trainer sistem wiper otomatis diperoleh nilai rata-rata $72,708 \%$ atau dalam kategori cukup valid, dengan demikian menunjukkan siswa lebih aktif dan termotivasi dengan adanya media pembelajaran trainer pada mata pelajaran sistem wiper otomatis.

\section{DAFTAR PUSTAKA}

Arikunto Suharmi. 2010. Prosedur Penelitian Suatu Pendekatan Praktik. Jakarta : Rineka Cipta.

Arikunto Suharmi. 2005. Dasar-Dasar Evaluasi Pendidikan. Jakarta : Bumi Aksara. Arsyad Azhar. 2011. Media pembelajaran. Jakarta : Raja Grafindo Persada. 
Bukit, Masriam. 2014. Strategi daninovasi pendidikan kejuruan dari kompetensi ke kompetensi, Bandung : CV. Alfabeta

Daryanto. 2016. Media pembelajaran peranannya sangat penting dalam mencapai tujuan pembelajaran. Yogyakarta : Gava Media.

Djemari Mardapi. 2008, Teknik Penyusunan Instrument Tes Dan Non Tes, Jogjakarta : Mitra Cendekia Press.

Muhammad Fatah Sururi. 2016. Pengembangan Media pembelajaran sistem pengapian otomotif untuk meningkatkan hasil belajar siswa TKR SMK N 1 Sapuran Wonosobo. Skripsi, tidak diterbitkan. Universitas Muhammadiyah Purworejo. Purworejo.

Rahayu Budi Dwi. 2012. Media Pembelajaran Trainer Elektronika Dasar Untuk Mata Pelajaran Elektronika Dasar. Skripsi, tidak diterbitkan. Universitas Negeri Yogyakarta, Yogyakarta

Slameto. 2013. Belajar dan Faktor-Faktor yang Mempegaruhi. Jakarta : Rineka Cipta.

Sudjana Nana. Rivai Ahmad. 1992. Media Pengajaran. Bandung : Sinar Baru.

Sugiyono. 2012. Metodologi Penelitian Pendidikan Pendekatan Kuantitatif, Kualtatif, dan R\&D. Bandung : CV.Alfabeta.

Suyitno, 2018. Metodologi penelitian tindakan kelas eksperimen dan R\&D disertai contoh dan aplikasi praktis, Bandung : CV. Alfabeta. 